\title{
Apply Unit Commitment Method in Power Station to Minimize the Fuel Cost
}

\author{
Adel Elhadi M. Yahya1, Mohamed Shaban², Yousif Yahya ${ }^{3}$ \\ ${ }^{1}$ Department of Industrial Engineering, Regdalen, Al-Zawia University, Zawiya, Libya \\ ${ }^{2}$ Department of Electrical Engineering, Surman High Institute, Surman, Libya \\ ${ }^{3}$ School of Electrical Engineering, Shanghai Jiao Tong University, Shanghai, China \\ Email: adel.e.yahya@gmail.com, Moh tub@yahoo.com, yousifadel11@Gmail.com
}

Received 11 June 2015; accepted 7 July 2015; published 14 July 2015

\begin{abstract}
The goal of this paper study is to schedule the power generation units to minimize fuel consumption cost based on a model that solves unit commitment problems. This can be done by utilizing forward dynamic programming method to determine the most economic scheduling of generating units. The model is applied to power station, which consists of four generating units. The obtained results show that the applications of forward dynamic programming method offer substantial reduction in fuel consumption cost. The fuel consumption cost has been reduced from $\$ 116,326$ to $\$ 102,181$ within a 24 -hour period. This means saving about $12.16 \%$ of fuel consumption cost. The study emphasizes the importance of applying modeling schedule programs to the operation of power generation units. Consequently, the less consumption of fuel is, the less losses of power and pollution will be.
\end{abstract}

\section{Keywords}

Unit Commitment, Forward Dynamic Programming, Generation Scheduling, Operation Cost

\section{Introduction}

The daily operation of the electric transmission grid is primarily concerned with the balance of satisfying the demand for electricity with the supply. This is accomplished keeping in mind adherence to all rules of physics and acceptable operation for security and reliability, while simultaneously minimizing the cost of electricity production. The cost of electricity is comprised of three components: capital and installation, operation and maintenance, and fuel consumption. For a thermal station, the cost of generating electricity is determined primarily by the cost of fuel burned. The fuel consumed is directly proportional to the amount of power being generated [1].

The electric power demand is generally higher during daytime and early evening when industrial loads are high, lights are on, and so forth, and lower during the late evening and early morning hours when most of the population is asleep. In addition, the use of electric power has a weekly cycle, the load being lower over weekend days than weekdays [2]. Therefore, predicting the load demand and building the property generator's 
on/off schedule can save money for the utility [3]. This problem is called unit commitment problem. Unit commitment problem is defined as a method to schedule generators economically in a power system in order to meet the requirements of load and spinning reserve. Usually this problem is considered over some periods of time, such as 24 hours of a day or the 168 hours of a week [4]. It is a much more difficult problem to solve. On the other hand, unit commitment problem is a nonlinear mixed integer problem. Most of conventional methods suffer from convergence problems, and always get trapped in a local minimum. Moreover, some techniques face the dimensionality problem especially when solving the large-scale system [1].

\section{Unit Commitment Analysis}

\subsection{Forward Dynamic Programming}

The forward dynamic programming method used has the following advantages:

1) Startups and shutdowns are not a problem;

2) Well-established theory;

3) Fast execution time.

This model is based on the priority list method but accounts for start-up and no-load costs, and minimum up and down times [5].

A priority list contains all state combinations of generators. The combinations or states are then listed from highest maximum net output power to lowest. When given the total load demand for any particular hour the list is used to determine which combinations are feasible. The feasible states include all combinations, which have a maximum net output power greater than or equal to the load demand [6]. The costs of all feasible states are calculated and the lowest cost combination is stored. Usually in the forward-dynamic programming method the cost function is assumed to be linear, however, in this case the function is a quadratic [7]. For any given state, the cost for that state is given by the following expression:

$$
\mathrm{F}(\mathrm{P})=\text { No-load cost }+ \text { Incremental fuel cost } \times \text { Power }+ \text { Constraint costs }
$$

In general, the total number of combinations is given by $(2 n-1)$. In a system with just five generators, that adds up to 31 different combinations. For most of those combinations the load demand isn't met. Other constraints affect which combinations are feasible. For most power plants, generators are use fossil fuels to move a turbine. These turbines take time to be started or turned off. Because of the time requirements, the machines have minimum up and down times. When a machine is turned on, it must run for a certain amount of time, and when the machine is turned off, the machine must remain off for a certain amount of time before being restarted.

In addition to thermal constraints, several other constraints must be considered when choosing generator combinations. Many power plants have more than one generator. In these plants, the utility may not employ enough crew people to start or shut down two generators simultaneously. Also, utilities are required to have enough capacity power to supply the network in the event of a generator failure [8]. This extra available capacity is known as "spinning reserve." Finally, some units must be running at all times. These "must run" units include [9] nuclear plants and units that supply steam heat outside of the plant.

There are several assumptions that must be made before dynamic programming can work.

1) A state consists of an array of units with specified units operating and the rest offline;

2) The start-up cost of a unit is fixed;

3) There are no shut-down costs;

4) There is a strict priority order, and in each interval a specified minimum amount of capacity must be operating [1].

\subsection{Dynamic Programming Solution}

The forward dynamic programming procedure is as follows:

- Each unit is either ON (1) or OFF (0);

- For $n$ units, each hour there are $2 \mathrm{n}$ ON/OFF combinations;

- Draw a tree with (\# hours) $\times 2$ nodes;

- For each node, calculate total dispatch cost;

- For each hour change, calculate transition cost $=$ cost of starts and stops;

- Eliminate transitions that are not feasible because of minimum up and minimum down times; 
- Build the last expensive total path;

- Input data:

The user should store the following data in a text file:

1) Number of generator units;

2) Minimum and maximum generation limits in (MW);

3) Incremental heat rate $(\mathrm{Btu} / \mathrm{kWh})$ or fuel consumption rate $\left(\mathrm{m}^{3} / \mathrm{MWh}\right)$;

4) No-load cost $(\$ / h r)$

5) Start-up cost (\$);

6) The fuel cost $(\$ / \mathrm{MBtu})$ or $\left(\$ / \mathrm{m}^{3}\right)$;

7) Minimum up time, maximum down time;

8) Initial condition;

9) Number of periods and the length of period in hours;

10) The total load demand for each period in (MW).

Program maximum dimensions:

maximum number of units $=10$;

maximum numbers of periods in the schedule $=8$;

maximum number of states in dynamic programming search $=256$.

- User Options:

The user is first asked to enter the name of the unit commitment data file. Next the user is asked to select priority order or complete enumeration for the solution. Note that there is only enough storage allocated for 256 states in the dynamic programming search routine. This means that up to an eight unit problem can have complete enumeration. For more than eight units the solution is limited to priority order [10].

Finally, the user has the option of including or not including minimum up and down constraints.

- Output:

The following results will be displayed:

1) Complete enumerations or priority order state table;

2) Units status at each interval period;

3) Production cost, and fuel cost at each period;

4) Minimum total cost for all periods;

5) Optimum commitment schedule.

\subsection{Application of Forward Dynamic Programming to a Typical Example}

To assess the validity of the computer program, the following typical sample example for which results are available is used.

Consider a system with 4 units to serve an 8 hour load pattern. Unit Characteristics are given in Table 1, and load pattern are given in Table 2. The goal is to find the optimum unit commitment without using a priority list [11].

Table 1. Unit Characteristics of sample example.

\begin{tabular}{|c|c|c|c|c|c|c|c|c|}
\hline \multirow{2}{*}{ Unit } & \multicolumn{2}{|c|}{ Output (MW) } & \multirow{2}{*}{$\begin{array}{c}\text { Incremental Heat Rate } \\
\text { Btu/kWhr }\end{array}$} & \multirow{2}{*}{$\begin{array}{c}\text { No-Load Cost } \\
\$ / \mathrm{hr}\end{array}$} & \multirow{2}{*}{$\frac{\text { Start-Up Cost }}{\$}$} & \multicolumn{2}{|c|}{ Minimum Times (hr) } & \multirow{2}{*}{$\begin{array}{c}\text { Initial Condition } \\
\text { Off }(-) / \text { On }(+)\end{array}$} \\
\hline & Min & Max & & & & Down & Up & \\
\hline 1 & 25 & 80 & 10,440 & 213 & 350 & 4 & 2 & -5 \\
\hline 2 & 60 & 250 & 9000 & 586 & 400 & 5 & 3 & 8 \\
\hline 3 & 75 & 300 & 8730 & 685 & 1100 & 5 & 4 & 8 \\
\hline 4 & 20 & 60 & 11900 & 252 & 0 & 1 & 1 & -6 \\
\hline
\end{tabular}

Table 2. Load pattern of sample example.

\begin{tabular}{ccccccccc}
\hline Time (hr) & 1 & 2 & 3 & 4 & 5 & 6 & 7 & 8 \\
\hline Load (MW) & 450 & 530 & 600 & 540 & 400 & 280 & 290 & 500 \\
\hline
\end{tabular}


In addition to the table, more problem information is given below:

Fuel cost: \$2/MBtu.

Losses, spinning reserve, and other aspects of the power system may be ignored for this problem.

For each time period in this problem, the number of states analyzed is limited to three $(\mathrm{X}=8)$.

The number of paths saved at the end of each step is limited to three $(\mathrm{N}=8)$

OPTIMUM COMMITMENT SCHEDULE

TOTAL COST $=74109.90 \$$

PERIOD STATE UNIT STATUS PCOST LOAD

1234 (\$/hr) (MW)

810 OFF ON ON OFF 10108500.000

710 OFF ON ON OFF 6366290.000

610 OFF ON ON OFF 6192280.000

510 OFF ON ON OFF 8308400.000

410 OFF ON ON OFF 10828540.000

39 OFF ON ON ON 12450600.000

210 OFF ON ON OFF 10648530.000

110 OFF ON ON OFF 9208450.000

DO YOU WANT TO RUN UNITCOM AGAIN? (Y OR N): N

From the above optimum commitment schedule, generator two and three would always be on and other generators in that period would not have any load. Also, in period 3, generator four would have been switched on before generator one. Since, generator one proved more cost efficient overall [12].

\subsection{Comparison of Results Forward Dynamic Programming}

The results of the forward dynamic programming method for the above sample example are compared with the results given in Wood and Wollenberg [1] which shown in Figure 1.

The same results of optimum commitment during 8-hours operation are obtained. Therefore, it can be seen that the present model and computer program are reasonable and valid, and can be used to perform unit commitment analysis by forward dynamic programming provided that good input data is available.

\section{Application of Unit Commitment to Power Station}

This station consists of 4-nuits each with a capacity of $152 \mathrm{MW}$ (i.e. the overall capacity of the station is 608 MW). The main fuel used in this station is Light fuel oil, the overall capacity of the station is expected to reach $660 \mathrm{MW}$, if gas is used as the fuel.

\subsection{Data for Power Station}

To acquire the economic distribution of energy loads among the working units, a relation between the fuel con-

\begin{tabular}{|c|c|c|c|c|c|c|c|c|c|c|}
\hline \multirow{2}{*}{ State Number } & \multirow{2}{*}{$\begin{array}{c}\text { Status of Units } \\
1234\end{array}$} & \multirow{2}{*}{ Total Capacity } & \multicolumn{8}{|c|}{ Hour } \\
\hline & & & 1 & 2 & 3 & 4 & 5 & 6 & 7 & 8 \\
\hline 15 & 1111 & 690 & $\bullet$ & - & $\bullet$ & • & - & $\bullet$ & • & $\bullet$ \\
\hline 14 & 1110 & 630 & - & - & $\bullet$ & • & - & $\bullet$ & • & $\bullet$ \\
\hline 13 & 0111 & 610 & $\bullet$ & • & $\bullet$ & $\bullet$ & - & $\bullet$ & • & $\bullet$ \\
\hline 12 & 0110 & 550 & $\bullet$ & $\bullet$ & $\bullet$ & $\bullet$ & $\bullet$ & $\bullet$ & • & $\bullet$ \\
\hline 11 & 1011 & 440 & • & $\bullet$ & - & $\bullet$ & - & $\bullet$ & • & $\bullet$ \\
\hline 10 & 1101 & 390 & $\bullet$ & $\bullet$ & $\bullet$ & $\bullet$ & $\bullet$ & • & • & • \\
\hline 9 & 1010 & 380 & • & • & • & • & • & • & • & • \\
\hline
\end{tabular}

Figure 1. Optimum path for the sample example. 
sumption and output power is needed. To get this relation, the output power of each unit is fixed for a long time interval, then readings are taken to record the amount of fuel consumed [13].

This process should be repeated many times at different outputs, to obtain sufficient points, and then the effective curves between fuel-consumption $\left(\mathrm{m}^{3} / \mathrm{h}\right)$ and output power $(\mathrm{MW})$ are drawn.

The figures in appendix (A), represent the actual curve characteristic of the four generating units of power station, they are obtained by testing the fuel consumption rate of each unit.

The fuel consumption rate equation is as follows, and its coefficients are given in Table 3 .

$$
F_{i}\left(P_{i}\right)=a_{i}+b_{i} P_{i}+c_{i} P_{i}^{2} \quad\left(\mathrm{~m}^{3} / \mathrm{h}\right)
$$

Here, ai, bi and ci are non-negative constants of ith generating unit.

$\mathrm{Fi}(\mathrm{Pi})=$ the fuel consumption for the unit by $\left(\mathrm{m}^{3} / \mathrm{h}\right)$.

$\mathrm{Pi}=$ the output power for the unit by $(\mathrm{MW})$.

The Related Parameters for the Fuel consumption functions of four units are as followed:

$\mathrm{F} 1=0.000227272 \mathrm{P}^{2}+0.17336364 \mathrm{P}+13.001818$

$\mathrm{F} 2=0.000121212 \mathrm{P}^{2}+0.18466667 \mathrm{P}+12.936364$

$\mathrm{F} 3=0.000238578 \mathrm{P}^{2}+0.17320256 \mathrm{P}+11.930839 ;$

$\mathrm{F} 4=0.000251748 \mathrm{P}^{2}+0.15965035 \mathrm{P}+13.565734$.

where, light fuel oil costs is estimated as $\$ 43.08 / \mathrm{m}^{3}$, The minimum and maximum generation limit, incremental fuel rate, no-load cost, starting-up cost, and minimum up and minimum down times for each unit are as given in Table 4.

The units are to be committed to serve a 24-hour load pattern, the load pattern (demand) of Power Station is shown in Figure 2, and data of this figure is illustrated in Table 5.

\subsection{Analysis of Power Station Using Unit Commitment}

To assess the validity of the computer program, the following typical sample example for which results are available is used.

Consider a system with 4 units to serve an 8 hour load pattern. The goal is to find the optimum unit commitment without using a priority list.

The application of the program for Unit Commitment analysis using forward dynamic programming method is used to analyze the power station [14].

The results of the forward dynamic programming (unit commitment) are the state of units (ON or OFF) at each hour that satisfy the load.

Table 3. Coefficients of the fuel consumption function of power station.

\begin{tabular}{cccc}
\hline Units & $\mathrm{a}$ & $\mathrm{b}$ & $\mathrm{c}$ \\
\hline 1 & 13.001818 & 0.17336364 & $2.27272 \times 10^{-4}$ \\
2 & 12.936364 & 0.18466667 & $1.21212 \times 10^{-4}$ \\
3 & 11.930839 & 0.17320256 & $2.38578 \times 10^{-4}$ \\
4 & 13.565734 & 0.15965035 & $2.51748 \times 10^{-4}$ \\
\hline
\end{tabular}

Table 4. Unit characteristics of power station.

\begin{tabular}{cccccccc}
\hline \multirow{2}{*}{ Unit } & \multicolumn{2}{c}{ Output (MW) } & Incremental Fuel Rate & No-Load Cost & Start-Up Cost & \multicolumn{2}{c}{ Minmum Times (hr) } \\
\cline { 2 - 7 } & Min & Max & $\mathrm{m}^{3} /$ MWhr & $\$ / \mathrm{hr}$ & $\$$ & Up & Down \\
\hline 1 & 50 & 149 & 0.1960 & 543 & 73 & 1 & 1 \\
2 & 50 & 150 & 0.2040 & 543 & 72 & 1 & 1 \\
3 & 50 & 150 & 0.2210 & 433 & 72 & 1 & 1 \\
4 & 50 & 152 & 0.2078 & 504 & 71 & 1 & 1 \\
\hline
\end{tabular}




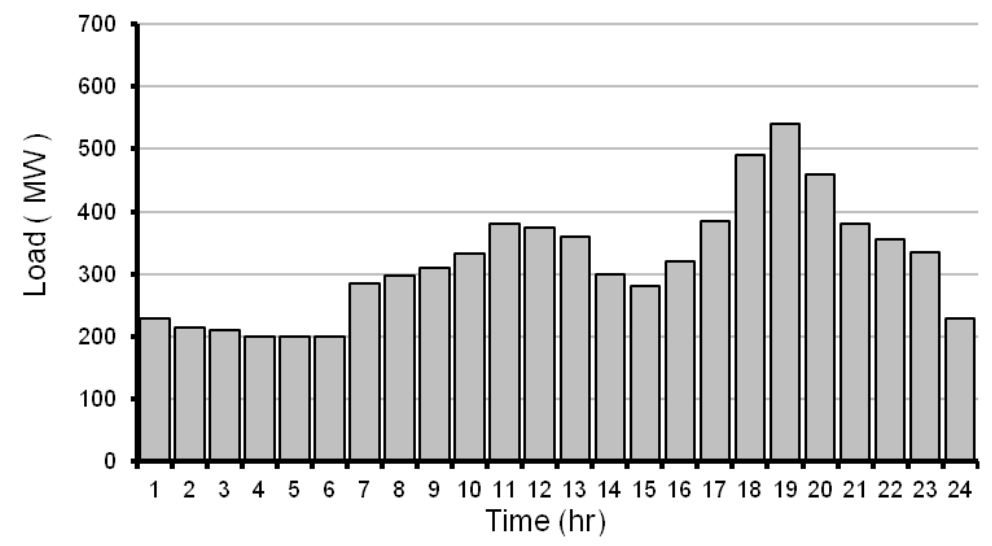

Figure 2. Daily load demand pattern of power station.

Table 5. Daily load demand data of power station.

\begin{tabular}{cccccc}
\hline Time $(\mathrm{hr})$ & Load $(\mathrm{MW})$ & Time $(\mathrm{hr})$ & Load $(\mathrm{MW})$ & Time $(\mathrm{hr})$ & Load $(\mathrm{MW})$ \\
\hline 1 & 230 & 9 & 310 & 17 & 385 \\
2 & 215 & 10 & 332 & 18 & 490 \\
3 & 210 & 11 & 380 & 19 & 541 \\
4 & 200 & 12 & 375 & 20 & 460 \\
5 & 200 & 13 & 360 & 21 & 380 \\
6 & 200 & 14 & 300 & 22 & 355 \\
7 & 285 & 15 & 280 & 23 & 334 \\
8 & 297 & 16 & 320 & 24 & 230 \\
\hline
\end{tabular}

\subsubsection{Input and Output to Unit Commitment Program}

The input data of power station are given in Table 4, and the load demand data are given in Table 5. The initial conditions of the 4-units assumed to be $-5,8,8,-6$ respectively [15].

\subsubsection{The Output Unit Commitment Program}

Unit status table used in dynamic programming search

\begin{tabular}{|c|c|c|c|c|}
\hline \multirow[t]{2}{*}{ State } & \multicolumn{4}{|c|}{ Unit Status } \\
\hline & 1 & 2 & 3 & 4 \\
\hline 1 & ON & ON & ON & $\mathrm{ON}$ \\
\hline 2 & ON & $\mathrm{ON}$ & ON & OFF \\
\hline 3 & ON & ON & OFF & $\mathrm{ON}$ \\
\hline 4 & ON & ON & OFF & OFF \\
\hline 5 & ON & OFF & $\mathrm{ON}$ & $\mathrm{ON}$ \\
\hline 6 & ON & OFF & ON & OFF \\
\hline 7 & $\mathrm{ON}$ & OFF & OFF & $\mathrm{ON}$ \\
\hline 8 & ON & OFF & OFF & OFF \\
\hline 9 & OFF & ON & ON & ON \\
\hline 10 & OFF & ON & ON & OFF \\
\hline 11 & OFF & $\mathrm{ON}$ & OFF & $\mathrm{ON}$ \\
\hline 12 & OFF & ON & OFF & OFF \\
\hline 13 & OFF & OFF & ON & ON \\
\hline 14 & OFF & OFF & ON & OFF \\
\hline 15 & OFF & OFF & OFF & ON \\
\hline
\end{tabular}


Figure 3 illustrated the optimal path of the during 24-hours period for our case study, where the unit combinations or states are ordered by maximum net capacity for each combination (complete enumeration).

In this case, unit 2 startup only at peak load (when load was 490MW, 541MW and 460MW at hour 18, 19 and 20 respectively) state 1 in the Figure 3. Unit 2 and unit 4 were shutdown at minimum load (from hour 1 to hour 8 and hour 24) state 6 , note, it is less expensive to turn on the less efficient peaking unit, number 3 for hour 1 , than to start-up the more efficient unit number 4 for the same period [16].

\subsection{Discussions of Results}

From the comparison between the current actual operation of power station and the results obtained by the present study using unit commitment it can denoted:

1) Table 6 illustrated difference between current actual operation and after applying unit commitment (UC) at hour $1(230 \mathrm{MW})$. Unit 2, and unit 4 shutdown, and unit 1, 3 startup, the saving in fuel cost per hour was found $=991.79 \$ / \mathrm{hr}$ at hour 1 ;

1) The current actual fuel consumption cost in power station is $\$ 116,326.15$ during 24-hours period;

2) After applying unit commitment the total cumulative fuel consumption cost will be $\$ 102,181.87$ during 24-hours;

3) The saving in fuel consumption cost per day was found to be $\$ 14,144.28$ within 24-hours period, of 4units only;

4) For a year of continuous operation saving in fuel consumption cost by $\$ 5,162,662.20(=14144.28 \times 365)$ within a year. This amount is a saving of $12.16 \%$ in the fuel cost [17].

\section{Conclusions}

From the results obtained in this study, the following conclusions can be stated:

1) Combination of unit commitment using forward dynamic programming for the analysis of power plant scheduling produces reasonable results;

\begin{tabular}{|c|c|c|c|c|c|c|c|c|c|c|c|c|c|c|c|c|c|c|c|c|c|c|c|c|c|}
\hline $\begin{array}{c}\text { Total } \\
\text { capacty }\end{array}$ & $\begin{array}{c}\text { Unit status } \\
1234\end{array}$ & $\begin{array}{c}\text { Status } \\
\text { number }\end{array}$ & 1 & 2 & 3 & 4 & 5 & 6 & 7 & 89 & 10 & 11 & 12 & 13 & 14 & 15 & 16 & 17 & 18 & 19 & 20 & 21 & 22 & 23 & 24 \\
\hline 1 & 1111 & 601 & - & - & - & - & - & - & $\bullet$ & - & $\bullet$ & $\bullet$ & - & - & 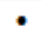 & & & & & & & - & - & & - \\
\hline 9 & 0111 & 452 & - & - & - & • & • & - & • & - • & - & & & - & & & & & & & & 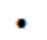 & - & & - \\
\hline 3 & 1101 & 451 & - & - & - & - & • & - & - & • & - & & & - & & & & & & & & $\bullet$ & - & & - \\
\hline 5 & 1011 & 451 & • & - & • & $\bullet$ & $\bullet$ & $\bullet$ & • & & & & & & & & & & & & & & & & 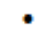 \\
\hline 2 & 1110 & 449 & $\bullet$ & - & - & $\bullet$ & $\bullet$ & - & $\bullet$ & 6 & . & & $\bullet$ & & . & & & $\bullet$ & - & $\bullet$ & $\bullet$ & - & - & & - \\
\hline 11 & 0101 & 302 & $\bullet$ & $\bullet$ & - & - & $\bullet$ & $\bullet$ & - & . & - & 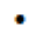 & 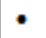 & & 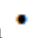 & & - & - & - & - & • & - & - & & $\bullet$ \\
\hline 13 & 0011 & 302 & - & $\bullet$ & $\bullet$ & - & $\bullet$ & $\bullet$ & - & - 1. & - & 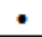 & - & - & - & & - & - & - & - & - & - & - & -1 & - \\
\hline 7 & 1001 & 301 & $\bullet$ & $\bullet$ & $\bullet$ & $\bullet$ & $\bullet$ & $\bullet$ & $\bullet$ & $\bullet$ & $\bullet$ & $\bullet$ & $\bullet$ & $\bullet$ & & & $\bullet$ & $\bullet$ & $\bullet$ & $\bullet$ & - & $\bullet$ & $\bullet$ & $\bullet$ & - \\
\hline 10 & 0110 & 300 & $\bullet$ & $\bullet$ & - & $\bullet$ & - & - & - & $\bullet$ & $\bullet$ & $\bullet$ & - & $\bullet$ & $\bullet$ & $\bullet$ & - & - & $\bullet$ & $\bullet$ & - & $\bullet$ & - & $\bullet$ & $\bullet$ \\
\hline 4 & 1100 & 299 & - & $\bullet$ & • & • & $\bullet$ & $\bullet$ & - & - & - & $\bullet$ & & $\bullet$ & - & $\bullet$ & - & - & $\bullet$ & $\bullet$ & - & $\bullet$ & - & - & 1 \\
\hline 6 & 1010 & 299 & 4 & & & & & & & - & - & - & • & • & - & - & - & - & - & • & - & - & - & • & 6 \\
\hline 15 & 0001 & 152 & - & - & - & - & - & - & - & - $\quad$ & - & - & & • & - & - & 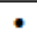 & - & - & - & - & - & - & • & - \\
\hline 12 & 0100 & 150 & - & $\bullet$ & • & • & • & - & - & - • & • & • & • & • & • & & • & • & • & • & • & • & • & • & • \\
\hline 14 & 0010 & 150 & $\cdot$ & $\bullet$ & $\bullet$ & • & • & - & - & • & $\bullet$ & $\bullet$ & & • & $\bullet$ & & - & - & - & $\bullet$ & $\bullet$ & - & - & $\bullet$ & - \\
\hline 8 & 1000 & 149 & - & $\bullet$ & • & • & • & - & - & - $\bullet$ & - & • & • & • & - & & - & • & • & • & • & • & • & • & - \\
\hline
\end{tabular}

Figure 3. Optimal path to operation of 4-units at power station.

Table 6. Difference between actual operation and applying UC.

\begin{tabular}{|c|c|c|c|c|c|c|c|}
\hline \multirow{2}{*}{ Operation } & \multirow{2}{*}{$\begin{array}{l}\text { Time } \\
\text { (hr) }\end{array}$} & \multirow{2}{*}{$\begin{array}{l}\text { Load } \\
\text { (MW) }\end{array}$} & \multicolumn{4}{|c|}{ Unit Number } & \multirow{2}{*}{$\begin{array}{c}\text { Fuel Cost } \\
(\$ / \mathrm{hr})\end{array}$} \\
\hline & & & 1 & 2 & 3 & 4 & \\
\hline Current & 1 & 230 & 60 & 65 & 50 & 55 & 4048.19 \\
\hline Applying UC & 1 & 230 & 117.6 & OFF & 112.4 & OFF & 3056.40 \\
\hline Difference & & & & & & & 991.79 \\
\hline
\end{tabular}


2) Although forward dynamic programming by using strict priority list reduces the dimensionality of the problem and is simpler to use, no optimal reduction has been achieved in the operation cost;

3) Forward dynamic programming by using complete enumeration gives the best possible savings in operation cost, but it required much more effort than strict priority list;

4) The application of unit commitment and to Power Station resulted in a considerable saving in fuel cost. In particular [18], the current fuel consumption cost at Power Station is very high (i.e. \$116,326 during the 24hour period) compared with $\$ 102,181$; this saving in fuel cost is about $12.16 \%$ and it amounts to about $\$ 5,162,662$ saving in a complete year of operation.

\section{References}

[1] Wood, A.J. and Wollenberg, B.F. (1996) Power Generation Operation and Control. 2nd Edition, Willey, New York.

[2] Kirchmayer, L.K. (1958) Economic Operation of power System. New York, Wiley.

[3] Huse, E.S. Power Generation Scheduling a Free Market Based Procedure with Reserve Constraints Included.

[4] Stevenson, Jr., W.D. (1982) Elements of Power System Analysis. 4th Edition.

[5] Hansen, P. and Mladenovc, N. A Separable Approximation Dynamic Programming Algorithm for Economic Dispatch with Transmission Losses.

[6] Chowdhury, B.H. and Rahman, S. (1990) A Review of Recent Advances in Economic Dispatch. IEEE Transactions on Power Systems, 5, 1248-1259. http://dx.doi.org/10.1109/59.99376

[7] Lai, L.L. (2001) Power System Restructuring and Deregulation. John Wiley and Sons, Ltd.

[8] Farag, A., Al-baiyat, S. and Cheng, T.C. (1995) Economic Load Dispatch Multiobjective Optimization Procedures Using Linear Programming Techniques. IEEE Transactions on Power Systems, 10, 731-738. http://dx.doi.org/10.1109/59.387910

[9] Sen, S. and Kothari, D.P. (1998) Optimal Thermal Generating Unit Commitment: A Review. International Journal of Electrical Power and Energy Systems, 20, 443-451. http://dx.doi.org/10.1016/S0142-0615(98)00013-1

[10] Sheble, G.B. (1999) Computational Auction Mechanisms for Restructured Power Industry Operation. Kluwer Academic Publishers. http://dx.doi.org/10.1007/978-1-4615-5157-7

[11] Bhattacharya, K., Bollen, M.H.J. and Daalder, J.E. (2001) Operation of Restructured Power Systems. Kluwer Academic Publishers. http://dx.doi.org/10.1007/978-1-4615-1465-7

[12] Talyor, G.A.B. Power System Economic. Edward Arnold, Ltd., London.

[13] Han, X.S., Gooi, H.B. and Kirsechen, D.S. Dynamic Economic Dispatch.

[14] Arroyo, J.M. and Conejo, A.J. Modeling of Start-Up and Shut-Down Power Trajectories of Thermal Units.

[15] Ouiddir, R., Rahli, M., Rahli, M. and Abdelhakem-Koridak, L. Economic Dispatch Using a Genetic Algorithm. A genetic.

[16] Aganagic, M., Awobamise, B., Raina, G. and McCartney, A.I. Economic Dispatch with Generation Contingency Constraints.

[17] Mantawy, A.H. and Abdel-Magid, Y.L. A New Fuzzy Unit Commitment Model and Solution.

[18] Andras Prekopa, R. Optimal Short Term. 